\title{
A MEMÓRIA DE UMA MESTRA: TRILHAS DE UM PENSAMENTO PEDAGÓGICO
}

\section{ADRIANNE OGÊDA GUEDES}

https://orcid.org/0000-0001-5632-4539

Universidade Federal do Estado do Rio de Janeiro

\section{IDUINA MONT'ALVERNE BRAUN CHAVES}

http://orcid.org/0000-0003-4732-8436

Universidade Feral Fluminense

RESUMO Este texto apresenta a memória e o ideário pedagógico de uma mestra. É um estudo da sua trajetória como educadora com vistas a apreender as ideias-força, a forma como elas foram se construindo e se constituindo ao longo do tempo, a presença das questões que circulavam nos diferentes tempos históricos vividos por ela e a potencialidade de sua atuação. Articulando as questões que a mobilizavam, à sua história profissional e à sua prática pedagógica, foi possivel identificar a marca da relação mestre e aprendiz como a sabedoria e a arte do mestre em se reconhecer no aprendiz, e ainda se reconhecer um aprendiz. O referencial teórico-metodológico se fundamenta na epistemologia da complexidade e na pesquisa narrativa. Toda a sua obra ressalta a necessidade de agirmos contra a barbárie, convocando a educação a constituir-se como uma promotora da solidariedade, do sentimento de pertença nos estudantes, no exercício da escuta e do diálogo, no acolhimento e no estabelecimento de relações pautadas pelo amor e pelo afeto. Envolvimento num processo formativo que se desenvolve pelo cultivo de almas.

Palavras-chave: Memória. Narrativa. Ideário pedagógico. Imaginário.

\section{ABSTRACT A TEACHER'S MEMORY: PATHS OF A PEDAGOGICAL WAY OF THINKING}

This paper presents the memory and pedagogical ideas of a teacher. It is a study of her career as an educator in order to grasp the power-ideas, the way they were built and constituted over time, the presence of issues that circulated in different historical times lived by her and the potentiality of her work. By articulating the issues that drove her forward throughout her professional history and her pedagogical 
practice, it was possible to identify the mark of the master-learner relationship as the wisdom and art of the master in recognizing herself in the learner, and even recognizing herself as a learner. The theoretical-methodological framework is based on Edgar Morin's epistemology of complexity and on narrative research. All of her work underscores the need to act against barbarism, calling for education to be a promoter of solidarity, a sense of belonging to the student community, of listening and engaging in dialogue, welcoming and establishing relationships based on love and affection. In a nutshell: Involvement in a formative process that develops through the cultivation of souls.

Keywords: Memory. Narrative. Pedagogical ideals. Imaginary.

\section{LAS MEMORIAS DE UMA MESTRA: CAMINHOS DE UM PENSAMENTO PEDAGÓGICO}

Este texto presenta la memoria y el ideario pedagógico de una maestra. Es una investigación acerca de su trayectoria como educadora con el objetivo de obtener las ideas-fuertes, la manera cómo se fueron construyendo y constituyéndose con los años, la presencia de temas que circulaban en los diferentes tiempos históricos vividos por ella y su potencialidad de actuación. Articulando los temas que la movían, su historia profesional y su práctica pedagógica, fue posible identificar la relación maestro y aprendiz como la sabiduría y el arte del maestro en reconocerse a sí mismo como un aprendiz. La teoría que fundamenta esta investigación es la epistemología da la complejidad de Edgar Morin y la investigación narrativa. Toda su obra destaca la necesidad de actuar contra la barbarie, invocando la educación como promotora de solidaridad, del sentimiento de pertenencia en los estudiantes, en el ejercicio del diálogo y de escuchar, y de establecer relaciones basadas em el amor. Involucramiento en una formación que se desarrolla por el cultivo de almas.

Palabras clave: Memoria. Narrativa. Ideario pedagogico. Imaginario. 
Não escrevo de uma torre que me separa da vida, mas de um redemoinho que me joga em minha vida e na vida. (MORIN, 1997, p. 10)

Para os navegantes com desejo de vento, a memória é um ponto de partida. (GALEANO, 1994, p. 96)

Como nos constituímos professoras?' ${ }^{1}$ De que modo as distintas experiências que vivemos impactam nosso ideário? Quais marcas se dão a ver em nossas produções acadêmicas dos encontros vividos e suas reverberações? Essas questões iniciais têm mobilizado nossas pesquisas e práticas no campo da formação de professores e impulsionaram, de modo especial, a pesquisa de doutorado em torno da vida e obra da professora Célia Linhares realizada pelas autoras deste artigo, orientanda e orientadora. A tese derivada dessa pesquisa intitula-se "Uma mestra da palavra: ética, memória, poética e (com)paixão na obra de Célia Linhares" (GUEDES, 2008), e teve como foco central a apreensão do pensamento pedagógico da professora Célia Linhares.

Célia é uma educadora emblemática, personagem significativo para o campo da educação brasileira e presença atuante em diferentes iniciativas na direção da valorização da profissão docente e na defesa de um ensino de viés democrático. Algumas de suas ações têm difusão nacional. Célia fez parte da primeira diretoria da Associação Nacional de Pós-Graduação e Pesquisa em Educação (ANPEd), da Associação Nacional pela Formação dos profissionais da Educação (ANFOPE) e foi respon-

1 Assumimos neste artigo o feminino ao nos referirmos às professoras, atividade que no contexto de nosso país tem sido assumida majoritariamente por mulheres (há muitos estudos que elucidam as razões históricas desse fenômeno da feminilização do magistério). Assumindo a necessidade de problematizar as questões de gênero que tensionam as marcas na linguagem que reforçam a predominância da lógica patriarcal, marcamos aqui também uma opção ética de dar relevo às ideias de uma sociedade mais equânime, cujos direitos da mulher e sua voz tenham espaço e destaque. sável pela construção do programa de pósgraduação da Universidade Federal Fluminense (UFF), nos anos 1970. Atuou na esfera da educação pública por meio de seus projetos, estreitando o diálogo entre a universidade e a escola básica.

A fim de identificarmos as matrizes de seu pensamento pedagógico, enfocamos seu percurso desde os anos de 1960, quando se graduou em Pedagogia, até meados dos anos 2000. Mergulhamos nesse percurso a partir de, basicamente, quatro fontes de pesquisa. Primeiramente, seus textos escritos desde a década de 1960; em segundo lugar, entrevistas semiestruturadas com distintas pessoas com os quais a professora Célia conviveu e trabalhou mais intensamente nos referidos períodos; finalmente, um conjunto de entrevistas com ela própria² e, por fim, 4) pesquisa bibliográfica sobre a história da educação brasileira, bem como consulta e apreciação de produções artísticas das épocas em questão (cinema, literatura, dentre outros). Vale dizer que para compreender a trajetória (o trajeto antropológico) da professora Célia foi preciso "viajar" com ela e com todo esse material, chegar-se a seu tempo, compreendendo as experiências que ela vivenciou de forma mais ampla.

As histórias pessoais não são meramente uma maneira de contar a alguém nossa vida. Elas são meios pelos quais identidades podem ser construídas, seu estudo revela sobre a vida social e cultural do contexto onde vivem os narradores. Estudar a educação é também estudar as experiências de vida em suas várias nuanças: as epifanias, os rituais, as metáforas, as rotinas.

Em nossa pesquisa, foi possivel não apenas compreender de forma pragmática a história-trajeto de Célia Linhares - os autores que a inspiraram, a tessitura de suas ideias, mas

2 As entrevistas realizadas com Célia Linhares e com seus parceiros de trabalho foram realizadas ao longo de 2007 nas casas dos entrevistados. 
também deixarmo-nos afetar por ela, colocando-nos ombro a ombro. Nesse sentido, a literatura, o cinema e os depoimentos dos entrevistados constituíram-se em fendas no tempo, que nos permitiram sentir, viver e partilhar do que suas narrativas nos convidavam a ver. 0 trajeto (antropológico) é aqui entendido como um caminho que em nível do imaginário, é percorrido por nossas pulsões subjetivas simbiotizadas com as intimações advindas do meio cósmico e social. (DURAND, 1989) Assim, nossas ações e palavras (discurso) não significam puramente a expressão dos nossos puros desejos: elas (ou eles) já se emitem misturadas, mais que misturadas, envolvidas com as tendências provenientes das pressões culturais, sociais e cósmicas.

Os estudos de Chaves (1999), sobre pesquisa narrativa, e os de Bueno, Catani e Sousa (2003), em sintonia com os de Josso (2004), dentre outros, foram referências fundamentais para compreender a relevância das práticas autobiográficas e biográficas na formação de professores e da professora Célia Linhares, nesse estudo. Durand (1989, p. 275) afirma que “[...] a memória seria ato de resistência da duração à matéria puramente espacial e intelectual e que ela (memória), e a imagem, ao lado da duração e do espírito, opõem-se à inteligência e à matéria, do lado do espaço [...]". Acrescenta, ainda, que a memória pertence de fato ao fantástico, dado que organiza esteticamente recordação e tem o caráter fundamental do imaginário, que é ser eufemismo.

A partir das relações entre a vida e a obra de Célia Linhares, destacamos ideias força, (ARAÚJO, 2004), isto é, ideias que apareceram de forma recorrente em seus textos, nos depoimentos de seus pares e em suas entrevistas, que se constituem em pilares nos quais erguerá sua forma de pensar a educação. Para esse artigo, fizemos um recorte, dando destaque ao panorama mais amplo das questões que se revelavam fortes, traçando assim um percurso em que os conceitos e questões de pesquisa se tecem e compõem o ideário da professora.

Para iniciarmos nossa viagem, tomamos como ponto de partida aspectos da vida de Célia-menina, que por serem especialmente significativos nos permitem compreender a Célia -mulher-mãe-professora e, de certa forma, a história das ideias pedagógicas da década de 1970 até os anos 2000. Vamos a eles.

\section{Célia, uma menina do Maranhão}

A menina Célia Linhares nasceu na cidade de São Luís, a ilha azul de Ferreira Gullar. Filha de Mário Soares e Alice Frazão Soares, fazia parte de uma irmandade de sete irmãos. Adhemar, Célia, Anna Maria, Yolanda, Rui - foi uma homenagem a Rui Barbosa, a quem o pai muito admirava -, Maria Teresa e Celso Antônio. O pai foi professor e advogado e o sentido de justiça guiava seus passos. Amava a poesia e recitava, sempre, enquanto se barbeava. Célia conta o quanto gostava do jeito sonhador e poeta do pai e admirava seu senso de justiça e seu amor pelos livros.

Uma passagem importante na infância de Célia fará com que ela saia do Maranhão em direção ao Rio de Janeiro, sua primeira migração (mas não a última...). o pai foi inspetor de ensino, defendia a escola e trabalhava pela limpeza dos processos educacionais. Conta Célia que as ideias de seu pai não agradavam a uns e a outros e em razão disso ele enviou a família inteira para longe do Maranhão, indo em seguida. A menina foi parar num navio, ela, seus irmãos e a mãe. Buscavam a segurança que já não mais havia.

Aos oito anos, outra passagem irá marcar Célia-menina. O pai, o pai sonho com quem ela tinha grande referência, morre. Abismo de tristezas. A menina desaprendeu a crescer. Para 
onde crescer sem o pai? A mãe surgiu como grande força de resistência, de sobrevivência. A parceria com os irmãos a fortalecia para enfrentar aquela que seria a primeira perda de um afeto tão querido para Célia. A mãe, embora fosse uma mulher mais objetiva e prática, achou de manter a presença viva do pai por meio da valorização de tudo aquilo que ele tanto tinha amado: os livros, os estudos, a justiça, o belo. A mãe cuidou do amor do pai, ajudando os filhos a crescerem com ele.

A frase da mãe revela a direção que a vida precisa tomar: "A vida é combate, que aos fracos abate, aos fortes e aos fracos só pode exaltar!." E Célia suportou, superou e continuou reaprendendo a crescer e a se firmar nos laços de afeto e de confiança na vida.

Conta Célia, que um dia na escola ela escreveu: "Tudo era dificil, mas as flores aqui e acolá, anunciavam a próxima primavera. Agora era florir"3.

O pai sonho e a mãe realidade são imagens que anunciam as matrizes míticas e imaginárias de sua visão de mundo, de educação, de cultura, da formação humana de professores. Imagens que se aglutinam em torno de núcleos semânticos ordenadores de sentido, configurados miticamente em temas de luta (universo heroico) e de aconchego (universo místico) ${ }^{4}$.

3 Em entrevista Célia Linhares recordou-se desse poema que escreveu na infância. Trata-se, portanto, de sua criação.

4 Para Durand (1989, p.41), os conjuntos simbólicos são essas constelações em que as imagens vêm convergir em torno de núcleos organizadores que a arquetipologia antropológica deve esforçar-se por distinguir através de todas as manifestações humanas da imaginação. No texto "A imaginação simbólica, Durand (1989) afirma que o imaginário apresenta-se como a tensão entre duas "forças de coesão", de dois "regimes", (Diurno e Noturno) cada um relacionando as imagens em dois universos antagonistas (o heróico e o místico). Esses universos, no estado normal e médio da atividade psíquica, acomodam-se em um outro subuniverso, que é o sintético. O Regime Diurno é o da antítese e os monstros hiperbolizados são combatidos por meio de símbolos antitéticos: as trevas são combatidas pela luz e a queda pela ascenção. Os esquemas verbais, de distinguir: separar/misturar, subir/cair. O Regime noturno é o da anti-frase está

\section{Trilhas do pensamento}

\section{pedagógico de Célia Linhares}

\section{nos anos 60: imagens e}

\section{simbolismos}

A década de 1960 caracterizou-se pelo início de novos papéis na vida de Célia Linhares. A graduação em Pedagogia na Universidade Federal do Maranhão (1957 - 1960), as aulas no ginásio municipal "Luiz Viana", o início da docência no ensino superior, a assessoria à Secretaria de Educação Maranhense, direção da Rádio Educadora do Maranhão, obtenção de título de mestrado na Universidade Federal do Maranhão, novas frentes que se abriam em sua vida profissional. É nessa década que Célia aproxima-se do movimento popular que será sempre tão caro em sua vida e obra. Na década de 1970, passagens marcantes da ditadura irão afetá-la de modo especial, influenciando sua forma de pensar a educação e o sentido que passa a dar à profissão, firmando ideias que nasciam e se fortaleciam na jovem professora. Simultaneamente, nascia a Célia mãe e esposa. Seu casamento com José Linhares, em São Luís, no ano de 1959, seria brindado nove meses depois com o nascimento de Mário, primeiro filho, em 1960.

Muitos foram os autores que influenciaram na construção do seu pensamento e da sua obra. De sua vida. A construção de si, de Célia, que se dá no movimento da sua trajetividade e constitui o seu imaginário. Dentre outros, diz Célia:

Max Weber, Marx, Wright Mills, Marcuse, Mc Luhan, Brokover, Bernard Show, Ângela Davis, até hoje ressoam em mim. [...] Diria, também, que na década de 60 , do século passado, intensifiquei o prazer em aprender e ensinar. Introdução à Educação, Filosofia da Educação, His-

sob o signo da conversão e do eufemismo, invertendo o sentido das imagens. Os esquemas verbais se caracterizam por reunir (amadurecer, progredir, voltar, enumerar) e confundir (descer, possuir, penetrar) 
tória da Educação, todos se entrelaçavam em minha existência política e militante. Em cada disciplina discutíamos os desdobramentos da LDB/1961, o pensamento de Fernando de Azevedo Anísio Teixeira, Lourenço Filho que sobressaiam em seus sonhos e empenhos diante de nossa da realidade educacional. Eram muito usados os livros de Jacques Maritain enquanto o pensamento de Teilhard de Chardin, Emanuel Mounier, Jean Paul Sartre, Simone de Beauvoir, Albert Camus, Miguel de Unamuno y Karl Jaspers, Heidegger, Kiekegaard, Kafka e tantos outros, começavam a se difundir e serem lidos por mim.

É possivel identificar, nos autores elegidos por Célia, a preocupação com um mundo que se queria mais justo e fraterno. A esperança numa nova organização complexa do social, fruto de uma ação educativa, também se evidenciavam. O humano, as interdependências, o respeito pela diferença, o diálogo com a mitologia e a poesia, a crítica às arrogâncias do cientificismo. Marcos teóricos que se evidenciam nos seus textos escritos, no seu discurso oral e na sua vida, como as suas metáforas obsessivas como o seu mito pessoal. Para ilustrar, trechos da entrevista realizada com ela em 2007:

O Teilhard de Chardin falava na complexidade. Ele nos fazia pensar sobre como mesmo nos momentos de aparente lentidão e de aparente inércia, os movimentos da vida, da inteligência e da sociedade não param de se processar. Depois retomo essa ideia como o movimento instituinte, movimentos que ainda não são visíveis, mas que subterraneamente eles agem. [...] Nas grandes esferas constitutivas da vida, dos vegetais, dos animais e do homem, do humano que ele chama de noosfera é que caminha o homem. É uma concepção dele muito centrada num humano que dialoga com o cosmos. Teilhard colocou um pensamento instigante para mim. Para ele, nós somos feitos de linguagem. Ele afirmara, que o falar não pode dispensar um exercício de auscultar o Ser. Sem isso, a fala desliza, facilmente, para os exercícios de tagarelice".
[...] Por tudo isto, não posso ter uma previsão certeira, do tipo encomendável do que será criado. Toda essa concepção se aproxima também do trabalho de Norbert Elias que vai rompendo com as idéias e práticas que sustentaram crenças em sujeitos onipotentes e em forças de vontade descomunais, para acompanhar os movimentos que vão se complexificando na história e que produzindo interdependências, trazem também surpresas, frustrações de planos e expectativas.

Assim, os inesperados não significam que a história seja um vale-tudo, nem que devemos deixar de nos esforçar nas direções que nos parecem mais corretas, mas o que eles sublinham é que os avanços históricos com a humanidade se recria, se reinventa não é algo manipulável, controlável.

Procurava contestar tudo isto, afirmando uma orientação mais larga, por isso em diálogo com a mitologia, a poesia - ainda como uma conexão com Heidegger- mas também com a filosofia oriental, contrapondo-me às arrogâncias do cientificismo de que o Brasil estava impregnado e, finalmente, me aproximando dos contos populares e infantis. "O patinho feio", por exemplo, que aborda a dificuldade de conviver com a diferença.

Ela estava ligada aos movimentos que se configuravam então, identificando-se com um projeto de nação que se queria mais justa, em que a educação tinha papel de destaque.

Era tempo dos Movimentos de Cultura Popular (MCP) e outras associações semelhantes, da vitalidade expansiva da União Nacional dos Estudantes (UNE), da Juventude Universitária Católica (JUC), das ações de Paulo Freire, da poesia de Ferreira Goulart. Célia queria um outro Brasil e defendida que os professores “[...] precisavam estar alertas para contribuir com essa Pátria que crescia dentro e fora de nós, com o sonho das Reformas de Base: a agrária, a educacional e todas as demais. Com suas contradições".

Além dos programas mencionados, Célia fala de um outro que realizava com o seu ma- 
rido, que "pescava" as questões em ebulição na cidade, dando espaço para discutir sobre elas no Rádio, exercício de olhar reflexiva e criticamente o tempo em que viviam e que versavam sobre questões educacionais, familiares e políticas que sacudiam a cidade. 0 programa da Rádio que objetivava falar ao pescador, ao homem da terra, à mulher trabalhadora, um circuito vivo de debates e embates, o tempo todo. "Não sabíamos as imensas proporções do que tocávamos, mas sentimos que era preciso resistir".

Foi uma experiência difícil para ela, não fora pela maravilha de estudar questões como a "fabricação de desejos" e até do "consentimento de morte" (Antropologia), as relações entre "Eros e Civilização", com suas ambiguidades e paradoxos (Filosofia), a potência das expectativas (currículo), educação, desigualdades e burocratização escolar (sociologia), mas pelo prazer de ver outras culturas em movimento (a negra lutando por seus espaços e reconhecimentos sociais, a cultura hippie, os resistentes manifestando-se, lutando, empenhando-se por todos os meios contra a guerra do Vietnã). Além de tudo isto, recebeu um prêmio da vida, o nascimento de sua filha Andréa.

Lá no Maranhão, diz Célia, "[...] em nossas conversas, lutávamos muito para que tivéssemos livro de história, que contasse a histórica das lutas do Maranhão". Depois, retoma com a discussão sobre as escolas Balaias e Cabanas tomando as lutas populares como um símbolo da potenciação do sonho, daquilo que não se realizou, mas também da tenacidade popular, da sua capacidade de resistir e criar. Em sintonia com seu tempo, Célia revela em suas experiências, estudos e reflexões a preocupação em construir uma prática educativa que incluísse a voz das pessoas em questão, valorizando suas experiências, saberes, cultura.

Sua militância no trabalho intelectual trazia uma visão crítica em busca de respostas inova- doras e alternativas concretas para a realidade brasileira. É expressiva sua preocupação com a adequação da escola ao mundo contemporâneo buscando na Filosofia os fundamentos de suas ideias, propostas e argumentos. A maneira de ver a realidade sob a perspectiva da justiça social é também uma marca de sua obra. Célia Linhares sempre se mostrou sensivel ao problema da desigualdade na sociedade e seus reflexos na educação.

A gravidade do movimento ditatorial brasileiro evidenciava-se. A Rádio foi fechada. Era só o início de pressões maiores que incidiriam sobre o país. Ela fala com pesar que

O golpe foi muito terrivel em 64 , mas foi em 68 que a ditadura mostrou toda a crueldade de que era capaz, aquelas listas nos aeroportos, os subversivos catados, os opositores presos, punidos e desaparecidos.

Célia, apesar dos medos e apreensões, reagia, e ressalta que "não havia outra via", reagir era o que era preciso ser feito. Revelava-se otimista diante das dificuldades e dos desafios que a realidade apresentava, acreditando que apesar de as ações nem sempre implicarem em resultados imediatos, "o levedo" estava fermentando. Dorothy, companheira da Rádio e das lutas no Maranhão nos anos 1960, comenta a respeito de Célia:

Sua militância no trabalho intelectual, com uma visão crítica em busca de respostas inovadoras e alternativas concretas para a realidade brasileira. Seu otimismo diante dos desafios que a realidade apresenta. Célia acredita que apesar de não vermos resultados imediatos, que o levedo está fermentando. Seu empenho é movido pela esperança de uma sociedade que amadurece e caminha para uma dimensão mais humanizada, onde todos terão a mesma oportunidade de realizar suas potencialidades e serem reconhecidos e respeitados como cidadãos e membros diferentes, mas iguais, numa comunidade mais fraterna. A imagem que tenho de Célia é a de uma água correndo em cima 
das pedras, que não amedronta, mas ela é movimentada e ela espirra para todo lado, assim, bonitinho, e ela faz um barulhinho espalhando a água, no rio com pedras, ela vem correndo, ela não para não. Vai respingando, molhando as coisas. (Entrevista, Dorothy, 2007)

A ideia de levedo diz respeito a sua esperança de uma sociedade que amadurece e caminha para uma dimensão mais humanizada, onde todos terão as mesmas oportunidades de realizar suas potencialidades e serem reconhecidos e respeitados como cidadãos e membros diferentes, mas iguais, numa comunidade mais fraterna. A renovação da educação formal e informal seria um grande veículo propulsor para esta utopia.

Com o propósito hermenêutico, sob o ponto de vista mítico-simbólico, buscamos compreender, as imagens e os simbolismos expressos e evocados dos discursos orais e escritos de e sobre Célia Linhares. Nesse percurso hermenêutico-simbólico, vamos fiando e tecendo os traços míticos latentes que nossa sensibilidade mítico-simbólica pode captar, das figuras antropológicas do obra-vida-obra em estudo.

Queremos deixar transparente que a noção de símbolo deve ser compreendida no quadro de uma hermenêutica que faz do símbolo e da interpretação conceitos correlatos, pois "existe interpretação onde existe sentido múltiplo, e é na interpretação que a pluralidade de sentido se torna manifesta" (RICOEUR, 1969, p. 16). E mais, o autor "atribui ao conceito de interpretação como sendo o trabalho de pensamento que consiste em decifrar o sentido oculto no sentido aparente, em mostrar os níveis de significação implicados na significação literal".(RICOEUR, 1969, p. 19). Durand (2004) trata dos símbolos, mediadores da energia psíquica, como a reunião de contrários mais fundamentais, a saber, "a energia eterna da alma e as manifestações temporais" que a imaginação colhe nas percepções, as lembranças da experiência e a cultura. Acrescenta, ainda, que é "pela interpretação dos símbolos que se realiza a individuação, isto é, o encontro da energia eterna, fundo do inconsciente não diferenciado e a sua refração através das situações temporais diferenciadas" (DURAND, 2004, p. 12). Esse autor traz, ainda, a contribuição de Jung para a hermenêutica, com a sua noção de arquétipo: “uma espécie de anjo-guia dos símbolos, que permite classificar as fontes da energia psíquica e põe em evidência, também, o papel da imaginação no processo individualizador". (DURAND, 2004, p. 37)

A esse respeito, Hameline (1986) afirma que a imagem-símbolo não se reduz ao mero efeito técnico de retórica. Ela é apreensão do inefável que está em causa. Para o autor "a imagem será declarada por essência simbólica e o símbolo como acepção" (HAMELINE, 1986, p. 127). Afirma, também, que a imagem-símbolo não se reduz ao mero efeito técnico de retórica, ela fala por outra coisa. Ela é a apreensão do inefável que está em causa. Para Hameline (1986) imagem será declarada 'por essência' simbólica. O símbolo, com uma acepção que ultrapassa largamente a retórica desacreditada, torna-se a 'figura geral de substituição'. Neste sentido, o discurso educativo precisa criar uma forte impressão junto aos seus leitores e as imagens devem possuir um caráter afetivo e um efeito semântico. E mais, afirma que "os discursos sobre educação, ao interagirem semanticamente, deixam o caminho aberto à atividade imaginativa/imaginante". (HAMELINE, 1986, p. 129)

A narrativa dos anos 1960 de e sobre Célia evocam imagens de fermentação e de água. As bebidas fermentadas segundo Chevalier e Gheerbrant (1994, p. 423), "são a imagem do conhecimento efervescente que permite ao espírito ultrapassar seus habituais limites, a fim de alcançar - pela intuição ou pelo sonho - o conhecimento profundo da natureza, o co- 
nhecimento do segredo das coisas". As significações simbólicas da água apresentam três temas fundamentais: fonte de vida, meio de purificação, centro de regenerescência.

\section{A década de 1970: medos e ousadias}

A criatividade está implícita em todas as teorias do humano como mais profundo nascedouro do processo de existir como pessoa, irrepetivel e original. (LINHARES, 1974, p. 97)

A década de 1970 marca fortemente sua vida. Seu irmão, Rui Frazão Soares é morto pela ditadura. Tal qual Antígona, sem poder enterrar seu irmão, Célia viveria a partir de 1974, junto com sua família, a busca por Rui, desaparecido. Busca que culminaria na confirmação de sua morte. Seu corpo nunca seria encontrado.

Tempos sombrios. Mas, sempre os anos 70 representarão uma passagem tenebrosa. Em1974, Rui foi aprisionado em uma feira de Petrolina. A dor e uma procura sem esperança sempre se faz presente, aumentando a falta e as indefinições de uma saudade que cresce enquanto o tempo vai arrastando consigo um tipo de emudecimento das testemunhas daquele tempo de tão inomináveis acontecimentos. Quando chegamos dos Estados Unidos, em 1970, trouxemos conosco nossos medos e encontramos fábricas de outros. (LINHARES, 2007, p. 27)

Todas as obras de Célia passam, a partir desse momento, a, de alguma forma, se inspirar na vida e presença de Rui. Apesar do abismo em que essa situação a jogou, Célia transmuta a dor em ação. A temática da memória, como aspecto fundamental para apropriação do presente, passa a habitar sua produção teórica. Lembrar, resgatar o movimento daqueles que lutaram por um Brasil melhor, é um pensamento que, tal como uma bússola, orienta suas ações e produções a partir de então.
No início dos anos 1970, entrou como professora na Universidade Federal Fluminense (UFF) e começou a sua luta, vencedora, para credenciamento e reconhecimento da Pósgraduação Stricto Sensu estabelecendo um diálogo estreito com a docência e a pesquisa. É, também, a época em que intensifica sua produção escrita.

Sobre a escrita, de início escrever era muito dificil, pois eu tinha vozes muito autoritárias dentro de mim, vozes da escola, do certo e do errado, impossivel e possivel e de fala muito idealizados. [...] 0 tempo foi passando e eu fui me autorizando a relaxar mais, a me encantar mais, a experimentar mais, a ter mais prazer. Assim, os inesperados não significam que a história seja um vale-tudo, nem que devemos deixar de nos esforçar nas direções que nos parecem mais corretas, mas o que eles sublinham é que os avanços históricos com a humanidade se recria, se reinventa não é algo manipulável, controlável.

Célia comenta sobre a profundidade mítica buscada por alguns filósofos que não se contentaram com uma racionalidade pragmática ou tecnocrática, buscando "a grandeza de penetração indutoras da acuidade perceptiva, reveladoras das estruturas fundamentais da existência humana" (LINHARES, 1974, p. 99). É possivel reconhecer, na afirmação de Célia sobre a insuficiência de um tipo de racionalidade para compreensão do mundo, sua crítica a um modelo de ciência que privilegia uma racionalidade estreita em detrimento de outras dimensões humanas. Lembremos que à época a visão hegemônica ainda era fortemente marcada por uma concepção dicotomizante do conhecimento, o que nos permite reconhecer que fecundava ali um pensamento divergente e insurreto.

Apresenta a ideia de que o humano por constituir-se como uma abertura, está exposto à vivência da ambiguidade. Dada sua infinitude de possibilidades de expressão, o homem 
não se esgotaria num único conceito, afirma Célia, e poderíamos defini-lo, justamente pela sua indefinibilidade e "imprevisibilidade surpreendente e auto-criadora" (LINHARES, 1974, p. $4-5)$.

Dentro de cada ser humano mora, não somente, o princípio masculino e feminino, mas a vida e a morte, o princípio da atividade e de passividade, o apego à rotina e o fascínio do extraordinário, a sedução do novo e o conformismo do habitual, uma existência finita dentro de um anseio infinito do Ser" (LINHARES, 1974, p. 22).

O importante para o homem não é chegar a nenhum lugar, não é o produto de seu trabalho, mas é sobretudo a procura de si, incessante, persistente e reveladora: a fidelidade à sua missão, o compromisso ao seu destino de homem, que é mister encontrar no âmago do seu existir pessoal e que ele descobre referenciando-se no Ser. Com este ponto referencial, o diálogo com as ambiguidades, caldeadas na crise, é altamente integrador. Então, o homem aprende a vivenciar as inusitadas alegrias do navegar, pela clarificação do seu ofício de ser gente.Percebe que navegar no azul imprevisivel da sua infinita missão, é preciso. Viver na rotina mecânica, em que só a sobrevivência é garantida, não é preciso. Neste sentido, "Navegar é preciso. Viver não é Preciso" (LINHARES, 1974, p. 29).

Se há uma multiplicidade infinita de caminhos nos quais as pessoas encontram a satisfação de suas buscas de auto-rrealização, de saúde, enfim de felicidade, por que não cultivar uma atitude de otimista expectativa, plena de respeito pelo caminho próprio em que cada pessoa busca a si mesmo?" (LINHARES, 1972, p. 13)

Em seus textos Célia abraça, cada vez com mais intensidade, temas tais como: o reconhecimento dos saberes dos sujeitos e da vida como fonte de saberes; a crítica às tendências dogmáticas e autoritárias que se impõem na escola e na sociedade; sua visão de ciência em sua construção incessante, na busca de conhecimentos e de ultrapassagens de limites, ressaltando a relatividade da verdade e suas conexões com cada época histórica e, sobretudo, nos movimentos sociais, populares.

Nesses percursos, aborda, dentre outras, a questão da imaginação e sua vinculação com a ciência, defendendo a ideia da imaginação como um processo criador, inseparável da realidade, mas também um instrumento para sua separação, capaz de forjar novas possibilidades para a educação. Resgata a ideia de utopia, como um caminho ainda não percorrido, ignoto, mas fecundo, para a construção de futuros possiveis. Critica as ideologias e ideias fantasiosas que, não só oprimem a educação, mas a distraem, impedindo que se desenvolvam processos mais conectados com as possibilidades concretas da educação escolar, em sintonia com as necessidades dos distintos grupos sociais que a demandam.

\section{Dos parceiros de Célia, alunos- professores}

Célia é inclusiva, ela é também de um pluralismo sadio. Com pluralismo sadio eu não quero dizer que ela é eclética, porque eclético faz a bagunça. 0 pluralismo faz associações, tira o melhor de cada fonte e percebe o fio condutor do conhecimento,que é um só. Complexidade também une, quando você divide você diminui, ela não dividia, ela incluía. E incluía com harmonia. Acho interessante que Célia mesmo com sua doçura, plantava na gente germes revolucionários. Era extremamente firme e doce nos momentos de embate, a Célia tem essa característica. Ela fala de uma forma doce, mas firme. Dentro da estrutura da universidade havia embates, ela com aquela característica dela de ser extremamente educada, dizia as coisas com a maior firmeza. 0 efeito disso era percebido no dia seguinte, as pessoas acabavam recebendo e acolhendo, não vou dizer sem responder não, mas ela conseguia tocar as pessoas, algumas diziam: A Célia quebrou a gente. (Balina em entrevista, 2007) 
Os embates tinham relação com a questão da qualidade acadêmica, a questão da visão de mundo, Célia lutava para que a Faculdade de Educação não fosse uma coisa doméstica, mas sim nacional e internacional. Isso foi um embate muito forte dentro da Universidade, pois havia coisas muito domésticas, a visão era $\mathrm{Ni}$ terói, Niterói, e quando muito um pouquinho do Estado do Rio. Outras questões foram também muito duras, como os embates para credenciamento do curso, recredenciamento do curso, em que Célia foi muito firme, e ao mesmo tempo, com a delicadeza que lhe é peculiar, ela falava todas as coisas que tinha que falar com as pessoas. Eu acho fundamental a contribuição de Célia para a educação brasileira. (Uma pedra sem a qual não se pode continuar. Uma pedra -exemplo e não uma pedra-obstáculo". (Jésus, entrevista 2007)

A Célia dos anos 1960 é ternura e firmeza. É Pedra, símbolo da terra-mãe, que é viva e dá vida. É construção, pedra sobre pedra que traz a noção de um edifício espiritual. Que guarda a grandeza da edificação. Pedra Filosofal do simbolismo alquímico de se constituir instrumento de regeneração. É Pedra Angular, pedra da finalização, do coroamento.

\section{Anos 1980: A abertura política, o povo volta às ruas}

Sombras
derrubam
sombras
quando a treva
está madura
Sombras
o vento leva
sombra
nenhuma
dura

(LEMINSKI, 1987, p. 105)

Nessa década, Célia defenderia sua tese intitulada La identidad cultural y el processo de educación en la América Latina (LINHARES,
1983), fruto de seu doutorado no Instituto de Filosofia Ciências e Letras, na área de Ciências da Educação da Univesidad Nacional de Buenos Aires.

De volta ao Brasil em 1983, retomou suas atividades na UFF, enquanto seu marido lançava-se, após a aposentadoria, em novo empreendimento abrindo uma agência de viagens, a ARGOS.

No Brasil Célia iniciou mais estreitamente seu vínculo com o Conselho Nacional de Desenvolvimento Científico e Tecnológico (CNPq), tornando-se pesquisadora. Em suas pesquisas evidencia-se a clara vinculação entre as questões da escola pública e da democracia, discutindo as sinuosidades da transição na formação de professores, incluindo nesta pesquisa comparações com a realidade brasileira e Argentina e Uruguaia.

Com uma maior abertura no campo da pesquisa, Célia pôde investigar questões como: 0 discurso pedagógico, sua elaboração retórica e sua legitimidade; a relação entre o Mestrado e a Escola Básica; a formação de professores nas sociedades em transição para a democracia e a Autonomia Universitária e a formação docente para os trabalhadores. Tratava-se de refletir sobre a formação sob diferentes aspectos e os rumos que esta tomava diante dos novos tempos.

Célia, em diálogo com Foucault (1989), parte da concepção de micro-política, ou na expressão do próprio Foucault, da microfísica dos poderes em jogo nas sociedades modernas. É assim que analisa em suas pesquisas a trama de poderes que circulam em todas as instâncias, em sua capilaridade, abrangendo instituições e atingindo todos os indivíduos. Tal perspectiva indica a presença do poder nas múltiplas relações humanas e nas instituições.

Há uma questão de fundo muito cara à mestra que aparece em suas pesquisas e pro- 
duções nesse período: a autonomia intelectual do professor. Conhecer os fundamentos de um autor e de seu fundamento - perspectiva que problematizava no campo da graduação de Pedagogos - de modo que fosse possivel forjar suas próprias formulações críticas e não meramente reproduzir ideias produzidas por outrem.

Nessa perspectiva, defende também a articulação entre Mestrado e Escola Básica, sugerindo um intercâmbio permanente entre essas duas instâncias. Célia considerava que havia um divórcio entre a escola experimentada e vivida e a pesquisa acadêmica. Pesquisando o perfil dos ingressantes nos programas de pós-graduação em Educação, mapeando as pesquisas que dialogavam com a escola na perspectiva de aproximar escola e universidade. Célia interessava-se em conhecer de perto as experiências dos professores, estreitando laços entre pesquisadores e docentes. Sua visão de pesquisa retirava-a das mãos de uma elite intelectualizada, desinteressada pelos problemas cotidianos da escola. Rompia também com a idéia de universidade como celeiro de produção de "verdades" a serem aplicadas pelos professores, de modo meramente reprodutor. Nessa década, crescem os estudos que enfatizam a compreensão de professor como sujeito crítico, investigador permanente de sua própria prática.

Um foco muito importante de atuação da professora, nos anos 1980, foi a sua participação e cocriação da ANFOPE e da ANPEd, cuja intensidade de trocas e debates entre os organizadores reavivava esperanças e confiança na capacidade associativa. Em outra frente de atuação participou a convite da professora Cecília Coimbra da formação do grupo Tortura Nunca Mais. A participação nesses espaços mais amplos de discussão e luta pelos direitos humanos e pela formação de professores trouxe para a Célia um sentido maior de pertenci- mento e maior capacidade de pronunciar-se, como uma forma de inscrever-s na vida e nas suas histórias.

Nos seus estudos sobre América Latina, fruto de seu doutoramento, investigou as questões da América Latina, focalizando o fortalecimento da identidade cultural e a crítica a uma mentalidade colonizada de desapreço pela própria cultura, sublinhando a idéia de latino-americanidade.

Anos 80. Anos do desbravamento de Célia. Anos da criação, que simboliza o fim do caos pelo advento de uma nova ordem, movida pela energia que organiza os caminhos.

\section{Anos 1990 aos dias atuais: 0 legado de Célia Linhares}

Movo-me na esperança enquanto luto e se luto com esperança, espero" (FREIRE, 2004, p. 47)

Nas palavras de Freire, a idéia de esperança que é luta traduz a trajetória de Célia. Sua vida foi se dando num fluxo em que esse elemento se fez presente em contextos diversos, com significados também diversos. A esperança, que em sua força propulsora, vai imprimindo esse jeito de apostar na vida a cada dia, tão próprio de Célia Linhares, com uma curiosidade, que em suas palavras "[...] a fazem levantar da cama todos os dias".

Nos anos 1990, após mais de 30 anos de trabalho acadêmico, Célia solicitou sua primeira aposentadoria, ao mesmo tempo em que via positivamente a possibilidade a afastamento de universidade, pela grande atração que a escola pública e o desafio de escrever literariamente sobre as experiências escolares exerciam sobre ela. Contudo o gosto pelo espaço de convivência com os estudantes e colegas, o movimento permanente de troca e aprendizado a mobilizavam muito. Não era algo do qual ela desejasse se distanciar. Um novo con- 
curso para a própria UFF, no qual se inscreveu na última hora para a disciplina de "Educação Comparada", fez com que ela se mantivesse na docência universitária, reafirmando esse como um espaço privilegiado de atuação.

Foi também nesse período que a professora viajou para a Espanha e para Londres para seu pós-doutoramento, primeiro na Universidad Complutense de Madrid e posteriormente na University of London (1992-1993). Primeira viagem longa sem a família, experiência que mobilizou novas aprendizagens e que envolviam maior autonomia. Novos laços e adaptações aos países novos, desafios que se descortinavam. Com relação às experiências acadêmicas e aos encontros intelectuais significativos foi quando travou contato com os estudos de Mariano Enguita, em Madri e de Francisco Varela, até então pouco conhecidos no Brasil. Retomou também o contato com Foucault, Norbert Eliase, Bourdieu dentre outros. Sua pesquisa envolvia pensar o trabalho do professor na construção da identidade da escola pública, enfatizando as questões ligadas às tecnologias.

Toda essa fertilidade de contatos e convívio com autores, ideias, espaços de reflexão foram vividos como entusiasmo crescente por Célia. Nessa época, estabeleceu parceria com a professora Regina Leite Garcia que também estava realizando o seu estágio de pós-doutorado, o que rendeu a produção de um livro de entrevistas sobre os dilemas do final de um século sob a perspectiva dos intelectuais. Seu trabalho vai ganhando maior visibilidade no Brasil, consolidando seu lugar como pesquisadora. Investiga as experiências instituintes em espaços de Educação Pública, destacando as potencialidades destas e caminhando na contramão de uma perspectiva crítica à escola. Incrementa também nesse período sua presença de forma mais sistemática nos sistemas públicos de ensino como consultora.
É um período de intensa produção escrita, com a publicação de coletâneas com diversos parceiros e de um livro que é emblemático de sua obra: Escola Balaia: um convite ao debate para a reinvenção de Caxias (LINHARES, 1999). Este livro traz o projeto elaborado por ela para a Educação Municipal de Caxias, RJ, onde sintetiza os princípios nos quais acredita para um projeto educativo. Diz do sonho de escola de Célia Linhares: A escola Balaia. É uma escola de esperança, de compromisso ético, de invenção do possivel (utopia), do afeto e do conhecimento.

Para finalizar, trazemos em destaque os princípios da Escola Balaia (LINHARES, 1999), que evidenciam os aspectos centrais que a mestra foi construindo ao longo de sua trajetória de pesquisas e práticas e nos ajudam a traçar um panorama dos aspectos nucleares de sua obra:

Princípio da emancipação pela autonomia dos sujeitos, que busca o fortalecimento dos sujeitos, reconhecendo a necessidade de que a autonomia escolar se alimente da cultura popular e da teórico-tecnológica, aproximando conhecimento da vida e, ao mesmo tempo, dando acesso à classe popular aos conhecimentos socialmente organizados. Autonomia que se estende para a escola - que precisa ser participativa e vida, e para o indivíduo, que implica em participação e fortalecimento dos vínculos da coletividade.

Princípio do atendimento da dignidade escolar, em que Célia chama atenção para as violências em suas múltiplas formas que vão sendo fortalecidas no cotidiano social, repudiando-as e conclamando para uma educação mais sensivel, que contribua para um estilo de produção mais humana.

Princípio da cidadania como aprendizagem escolar, em que afirma a importância de reconhecer a educação como espaço de direito e de formação do cidadania. Entende 
por cidadão aquele que se apropria de sua história, do valor de sua terra, que tem seus direitos vitais garantidos - educação, saúde, moradia, respeito. Concebe o conhecimento; o "saber com sabor" é um direito do cidadão e uma necessidade na construção de indivíduos capazes de intervir na sociedade de forma potente, plenos de seus saberes. Acredita também nas relações entre escola e comunidade, como vias de fortalecimento de ambas as instâncias.

Célia traz a marca da epistemologia da complexidade em todos os seus saberes e fazeres. É luz e sombra. É aurora e crepúsculo. É sol e lua. A simbologia da harmonia dos contrários em todas as suas nuanças.

\section{Considerações finais}

Este trabalho nos leva a concluir que a obra da educadora, Célia Linhares, ressalta a necessidade de agirmos contra a barbárie, convocando a educação a constituir-se como promotora da solidariedade, do sentimento de pertença no exercício da escuta e do diálogo, no acolhimento e no estabelecimento de relações pautadas pelo amor e pelo afeto. “Os princípios da emancipação pela autonomia dos sujeitos, da dignidade e da cidadania como aprendizagem escolar" são nucleares no ideário pedagógico da professora Célia Linhares.

Célia Linhares é uma Grande Mestra, que lança palavras a seus discípulos e pesca as que eles proferem, que aposta na autonomia e na potência do outro, reconhecendo seus saberes e suas diferenças. Uma Mestra que vive permanentemente a própria luta e esforço para cunhar esperanças, para pensar com sabedoria. Uma sabedoria, que como nos dizem Morin e Le Moigne (2007, p. 202), “implica na auto-ética, evitando a baixeza, evitando ceder às pulsões vingativas e mal- dosas". Para isso, ele nos diz, é preciso muita autocrítica e auto-exame. "A autoética é antes de tudo uma ética da compreensão. Devemos compreender que os seres humanos são seres instáveis, nos quais há possibilidades do melhor e do pior [...]" (MORIN, 1998, p. 61). Mestra do amor, que se deixa contaminar pela verdade do outro, não impondo a sua própria, encontrando a sua própria através da alteridade.

Mergulhar na obra/vida de Célia Linhares foi uma aventura intelectual das mais instigantes. Confirmamos as palavras de Bosi (2004, p. 69), de fato "a memória dos velhos desdobra e alarga de tal maneira os horizontes da cultura que faz crescer junto com ela o pesquisador e a sociedade onde se insere". Com a ressalva de que, diferentemente de Bosi $(2003 ; 2004)$ que trabalhou apenas com velhos nas duas obras com que travamos contato, escutamos pessoas de variadas idades. 0 ponto de semelhança é que, independente do fator idade, escutar experiências diferentes da nossa própria, que nos reportam a outros tempos, outras realidades, formas singulares de ver o mundo a partir de outras perspectivas, constitui-se em uma vivência de alargamento de horizonte, sem dúvida. Para quem pesquisa e para o campo das ciências humanas.

Ainda com Bosi (2003), reafirmamos que uma história de vida não é feita para ser arquivada ou guardada como coisa, mas existe para transformar a cidade onde ela floresceu . Talvez o principal mérito desse texto seja: dar visibilidade a uma trajetória, que se cruza com tantas outras, que revela tempos, movimentos, história. A história de uma vida, de um país e no caso de nosso interesse específico, da própria educação - seus movimentos, embates, ideias e caminhos. Uma trajetória que vale a pena ser contada e conhecida, guardada, no sentido que Antonio Cícero (1996, p. 337) nos indica: 


\section{Guardar}

Guardar uma coisa não é escondê-la ou trancá-la.

Em cofre não se guarda coisa alguma.

Em cofre perde-se a coisa à vista.

Guardar uma coisa é olhá-la, fitá-la, mirá-la por admirá-la,

isto é, iluminá-la ou ser por ela iluminado.

Guardar uma coisa é vigiá-la, isto é, fazer vigília

por ela, isto é, velar por ela, isto é, estar acordando

por ela, isto é, estar por ela ou ser por ela.

Por isso melhor se guarda o vôo de um pássaro

Do que pássaros sem vôos.

Por isso se escreve, por isso se diz, por isso se publica,

por isso se declara e declama um poema:

Para guardá-lo:

Para que ele, por sua vez, guarde o que guarda:

Guarde o que quer que guarda um poema:

Por isso o lance do poema:

Por guardar-se o que quer guardar.

\section{Referências}

ARAÚJO, Alberto Filipe. Educação e imaginário: da criança mítica às imagens da infância. Maia, Portugal: Instituto Superior da Maia, 2004.

BOSI, Ecléa. Memória e sociedade, lembranças de velhos. São Paulo: Companhia das letras, 2003.

BOSI, Ecléa. 0 tempo vivo da memória, ensaios de psicologia social. São Paulo: Ateliê Editorial, 2004.

BUENO, Belmira Oliveira.; CATANI, Denice Barabara; SOUSA, Cynthia Pereira (Org.). A vida e o oficio dos professores: formação contínua, autobiografia e pesquisa em colaboração. São Paulo: Escrituras, 2003.

CíCERO, Antônio. Guardar. In: Guardar: poemas escolhidos. Rio de Janeiro, RJ: Record, 1996.

CHAVES, Iduina Mont'Alverne Braun. A pesquisa narrativa: uma forma de evocar imagens da vida de professores. In: TEIXEIRA, Maria Cecilia Sanchez (Org.). Imagens da cultura: um outro olhar. São Paulo: CICE/FEUSP, 1999. p. 121-138.

CHEVALIER, Jean; GHEERBRANT, Alain. Dicionário de simbolos: (mitos, sonhos, costumes, gestos, formas, figuras, cores, números). Rio de Janeiro: José Olympio, 1994.

DURAND, Gilbert. A imaginação simbólica. São Paulo: Cultrix/EDUSP, 1988.

DURAND, Gilbert. Campos do Imaginário. Textos reunidos por Danielle Chauvin. Lisboa: Instituto Piaget, 1989.

DURAND, Gilbert. 0 imaginário. Ensaio a cerca das ciências e da filosofia da imagens. Rio d Janeiro; DIFEL, 2004.

FOUCAULT, Michel. Microfisica do poder. $8^{\text {a }}$ ed., Rio de Janeiro: Graal, 1989.

FREIRE, P. Pedagogia da esperança. Rio de Janeiro: Paz e Terra, 2004.

GAleAno, Eduardo. As Palavras Andantes. Porto Alegre: L\&PM, 1994.

GUEDES, Adrianne Ogêda. Uma mestra da palavra: ética, memória, poética e (com)paixão na obra de Célia Linhares. 2008, 426f. Tese (Doutorado em Educação) - Pós-graduação em Educação, Uni- 
versidade Federal Fluminense, Niterói, RJ, 2008.

HAMELINE, Daniel. L'Éducation, ses images et son propos. Paris: Éditions ESF, 1986.

JOSSO, Marie-Christine. Experiências de vida e formação. São Paulo: Cortez, 2004.

LEMINSKI, Paulo. Distraídos venceremos. São Paulo: Companhia das Letras, 1987.

LINHARES, Célia Frazão. O poder das expectativas e o self. Revista da Faculdade de Educação. Vo. 3, n. 3, p. 15-25, Niterói : EdUFF, 1972.

LINHARES, Célia Frazão. Introdução a ontologia da criatividade, ensaio de filosofia educacional sob a metodologia fenomenológica. 1974, 110f. Tese (livre Docência). Universidade Federal Fluminense (UFF), Niterói, RJ, 1974.

LINHARES, Célia Frazão. La Identidad Cultural y el processo de Educacion em La América Latina. 1983, 210f. Tesis (Doctorado en Ciencias de la Educación), Facultad de Filosofia y Letras, Universidad Nacional de Buenos Aires, Buenos Aires, 1983.

LINHARES, Célia Frazão. Escola Balaia: um convite ao debate para a reinvenção de Caxias. Caxias: Editora Caburé, 1999.

LINHARES, Célia Frazão. As coisas findas, elas ficarão? Rio de Janeiro: mimeo, 2007.

MORIN, Edgar. A inteligência da complexidade. São Paulo: Edição Peirópolis, 1997.

MORIN, Edgar. Amor, poesia e sabedoria. Rio de Janeiro: Bertrand Brasil, 1998.

MORIN, Edgar; LE MOIGNE, Jean Louis. A inteligência da complexidade. São Paulo: Peirópolis, 2007.

RICOEUR, Paul. O conflito das interpretações: ensaios de hermenêutica. Rio de Janeiro: Editora Imago, 1969.

Recebido em: 29.10.2019

Revisado em: 28.03.2020

Aprovado em: 30.03 .2020

Adrianne Ogêda Guedes é professora e pesquisador do Programa de Pós-graduação em Educação da Universidade Federal do Estado do Rio de Janeiro (UNIRIO). Doutora em Educação pela Universidade Federal Fluminense (UFF). Líder do Grupo de Pesquisa Formação e Ressignificação do Educador: Saberes, Trocas, Arte e Sentidos (FRESTAS/CNPq). E-mail: adrianne.ogeda@gmail.com

Iduina Mont Alverne Braun Chaves é professora e pesquisadora do Programa de Pós-graduação em Educação da Universidade Federal Fluminense (UFF). Diretora Geral do Colégio Universitário Geraldo Reis (UFF). Doutora em Educação pela Universidade de São Paulo (USP). Doutorado Sanduíche na Universidade de Illinois, USA. Líder do Grupo de Pesquisa Cultura, Imaginário, Memória, Narrativa e Educação (CIMNE/UFF/CNPq). Pesquisadora Colaboradora do Centre de Recherche em Education de Nantes (CREN), França. Pesquisadora do GRIFARS-UFRN-CNPq. E-mail: iduina@globo.com 